\title{
Review of Hmong-Related Health Problems: A Quick Guide for Healthcare Providers
}

\author{
Ali H. Ali ${ }^{1}$, Mandip S. Kang ${ }^{1}$, Kamalmeet Kaur ${ }^{1}$, Saja Al adhami ${ }^{2}$, Candice R. Yuvienco ${ }^{3}$ \\ 1. Internal Medicine, University of California San Francisco-Fresno, Fresno, USA 2. Internal Medicine, Community \\ Regional Medical Center, Fresno, USA 3. Internal Medicine/Rheumatology, University of California San Francisco- \\ Fresno, Fresno, USA
}

Corresponding author: Ali H. Ali, aali@fresno.ucsf.edu

\begin{abstract}
The people of Hmong descent are one of the largest resettled communities in the United States (US). The Central Valley of California is well known to be the home to the largest Hmong population in the US. However, despite the presence of such a large Hmong community in the Central Valley, our knowledge of their cultural perceptions of medicine is limited. Based on local Central Valley health providers' experiences and observations, the Hmong people have a number of health-related challenges that differ from those of the general population, and this should be considered when dealing with their healthcare needs. In this report, we present a quick guide about the Hmong community and their health-related issues. We hope this will help clinicians and researchers better understand the Hmong community, which in turn would help provide a better quality of healthcare to the Hmong people and stimulate intellectual curiosity among healthcare providers towards this unique Asian ethnicity.
\end{abstract}

Categories: Genetics, Internal Medicine, Epidemiology/Public Health

Keywords: hmong, homng-related health issues, health disparities, epiddemiology

\section{Introduction And Background}

The Hmong are an Asian ethnic group originally from southern China that later migrated to the northern regions of Laos, Vietnam, and Thailand. Since the 1970s, large numbers of Hmong have come to the United States (US) as refugees with their last major resettlement happening in 2006 [1-2]. The aim of this review is to provide healthcare workers with a concise guide that should provide clarity regarding most of the Hmong-related health issues and their cultural beliefs that affect their management in order to enhance their care.

The Hmong in the US are predominantly from Laos and were recruited by the US Central Intelligence Agency to fight in the "Secret War" in Laos in 1965. Their role was to fight the communists in Laos, to prevent the North Vietnamese from coming through Laos into South Vietnam. The Secret War ended in 1975 with the conclusion of the Vietnam War. Many Hmong fled to refugee camps in Thailand and subsequently migrated to the US [2]. Eventually, the Hmong moved to California, Minnesota, Wisconsin, Ohio, and North Carolina, where large numbers of clan groups reside [3].

Received 06/15/2020 Review began 07/04/2020 Review ended 08/05/2020 Published 08/17/2020

(c) Copyright 2020 Ali et al. This is an open access article distributed under the terms of the Creative Commons Attribution License CC-BY 4.0., which permits unrestricted use, distribution, and reproduction in any medium, provided the original author and source are credited.
Having basic knowledge about Hmong traditions is an essential part of taking care of their healthcare needs. The Hmong clans play an important role in maintaining the mental and general well-being of the Hmong community. In the US, approximately $70 \%$ of the Hmong still practice traditional, animist ancestor worship and Shamanism, whereas the other $30 \%$ have converted to Christianity [4]. The shaman is an individual who, according to Shamanism, travels between the visible and the spirit worlds through ritual practices that are conducted for purposes of healing, divination, and control over natural events. They are believed to be important sources of mental health support for the Hmong community [5].

Healthcare providers should be mindful that the Hmong language lacks vocabularies and terms related to body anatomy, pathologies, and disease process. For example, there is no word in the Hmong language that refers to "cancer". Therefore, interpreters may need to explain in more words and sentences to deliver the best description of the disease [6].

\section{Review}

\section{Hmong demographics}

It is estimated that there are 309,564 Hmong in the US. California has the largest Hmong population followed by Minnesota and Wisconsin. The Hmong live mainly in the San Joaquin Valley area in California, and Fresno, Sacramento, and Merced are among the top 10 cities where they reside. Fresno has the second largest population of the Hmong in the US, after Saint Paul, Minnesota, which has the largest Hmong population in the US [7-8]. 
The Hmong people have a median age of 24.5 years compared to 38.1 years among the general population in the US; $60.6 \%$ of the Hmong are between the ages of 18 and 64 , compared to $61.8 \%$ in the same age group among the general population. The Hmong who reside in the Central Valley of California mainly work in farming as they were influenced by the agricultural environment in the Valley. Similarly, in North Carolina, most of the Hmong run poultry and egg farms. On the other hand, many of the Hmong in Michigan have turned to owning and operating their own ventures within the food industry. Although the Hmong are in the process of developing their own distinct Hmong-American culture, they still preserve the best features of their language and traditions [8].

In terms of social determinants of health, current data suggest that the Hmong might be at risk of poor health conditions in general. The Hmong have an average household income of $\$ 45,776$, compared to $\$ 66,201$ among Asian Americans in general. Additionally, 23.2\% of the Hmong have lower than a high school diploma compared to $12 \%$ of the general population, and $76.8 \%$ have higher than a high school diploma compared to $88 \%$ among the general population [7]. Also, 87\% of Hmong in the US speak English less than very well, compared to $60 \%$ of the Asian American population in general [1].

Epidemiological research and survey data have improved our overall understanding of health disparities and how they arise, which in turn should help facilitate a better approach to community-based medical management. However, much of the research has focused on large (umbrella) racial and ethnic minority categories. For example, nationwide studies in the US, such as those conducted by the Centers for Disease Control and Prevention (CDC), National Center for Health Statistics (NCHS), and Behavioral Risk Factor Surveillance System (BRFSS) have defined the umbrella of racial and ethnic minorities as "White, Black or African American, American Indian or Alaskan Native, and Asian”, effectively making racial and ethnic minority subgroups invisible. This generalizes certain communities and aggregates them under one single group, irrespective of the vast differences within them. National health research has been conducted with Asian Americans as an aggregate group, or with the six larger Asian American subgroup populations (Asian Indian, Chinese, Filipino, Japanese, Korean, and Vietnamese) at a disaggregate level. The Hmong community, even with its diverse culture and beliefs, were accounted for under Asian Americans. Moreover, there are many other sizable Asian American groups in the US who, like the Hmong, have not been disaggregated in national studies: Pakistani $(409,000)$; Cambodian $(276,000)$; Thai $(237,000)$; Laotian $(232,000)$; Taiwanese $(230,000)$; Bangladeshi $(147,000)$; and Burmese $(100,000)$. These groups have different cultural backgrounds and vastly different histories, including differences in diet, cultural practices, healthrelated beliefs, education, socioeconomic status, and geographical origins. Thus, "determinants of health," such as income and education, may vary considerably between and among each of these subgroups and could result in significant differences in health outcomes. Little is known as to whether there are differences between the umbrella groups and any of the subgroups and within the subgroups themselves [1].

\section{The Hmong's conception about illnesses}

According to Shamanism, the Hmong believe that diseases are caused by a departed ancestral spirit or the souls of those who have suffered an illness. The latter explains why certain Hmong believe that illness results from the separation of body and soul, which may or may not be related to the act of offending an ancestor, rather than a biological process. Moreover, the wish of the soul to leave the body it occupies is another concept related to the disease process according to the Hmong culture. As a result of these conceptions, the Hmong believe that western medicine is not the best treatment option for the illnesses, and they can instead be treated by a traditional healer called the shaman. The shaman is responsible for duties similar to that of a psychologist, a doctor, and a minister [5].

The shaman is the person who can ensure contact between the visible and the spirit world through specific spiritual activities. According to the Hmong culture, if a shaman's ritual of soul-calling fails to bring back the soul to the sick individual, the person's condition might get worse, even leading to death [5,9]. Due to these beliefs, many Hmong families have difficulty in understanding the concept of disease transmission through microorganisms, and they may even refuse western medicine-based treatments [9]. Home remedies and herbal treatments are still widely used among the Hmong community. The importance of biomedicine is known among Hmong communities, but traditional diagnosis and herbal or spiritual treatments are usually accorded the first preference [5]. It is important for healthcare providers to be aware of these conflicts between biomedical practices and Hmong beliefs. For instance, Hmong people may be hesitant to undergo surgical procedures due to the belief that they may lose their soul while being unconscious under anesthesia. After any general anesthetic induction involving a Hmong patient, it may be important to conduct a soulcalling ceremony in the operating room to recall the lost soul. Furthermore, the surgical removal of a body part may clash with the Hmong belief in reincarnation, which explains why some Hmong refuse surgical interventions [5].

\section{Hmong-related health issues}

The Hmong community has been found to have higher rates of infection-related cancers like nasopharyngeal carcinoma, gastric cancer, hepatic cancer, and cervical cancer. The prevalence of these cancers among the Hmong is higher compared to the commonly found cancers among the rest of the US population, such as lung, breast, and colorectal cancers [10-11]. For instance, hepatitis B-linked liver cancer disproportionately 
affects Hmong Americans as the incidence rate is six times greater than that among non-Hispanic whites [12]. The Hmong are reported to have a high prevalence of hepatitis B virus, ranging from $3.41 \%-16.7 \%$, which is on the higher side compared to the prevalence rate of $0.15 \%-1.27 \%$ with other Asians, Caucasians, African Americans, Hispanics, and Native Americans [13,14]. A low rate of Hepatitis B screening (24\%) was reported among the Hmong adults in Sacramento [12]. Furthermore, Hmong has the highest liver cancer mortality rate compared to other Asian ethnicities [15]. Similarly, nasopharyngeal cancer mortality rates are 10.4 for the Hmong compared to 0.2 and 1.7/100,000 for non-Hispanic whites and Asians/Pacific Islanders, respectively [16]. Cervical cancer incidence and mortality rates among the Hmong women are three to four times higher than Asians/Pacific Islanders and non-Hispanic white women [17]. Due to poor access to health services, it is not surprising that the Hmong are more likely to be diagnosed with cancer at an advanced stage [15].

The main contributors to the high cancer morbidity and mortality among the Hmong are likely attributed to genetics, problems in access to health services, and diet-related issues. In a study of cancer-related genetic polymorphisms, the Hmong were found to have significant risk genetic factors associated with cancer etiology and prognosis [10,18-20]. A study in Minnesota showed that newly arrived Hmong refugees from Thailand had significant cardiovascular risk factors on arrival, including obesity, hyperglycemia, hyperuricemia, renal insufficiency, and hypertension [21].

Another study that investigated the clinical features of cerebrovascular accidents in the Hmong compared to non-Hispanic white people showed that the Hmong suffer from poorly controlled risk factors like diabetes and had higher incidences of small vessels and intracranial atherosclerotic disease, but low incidence of carotid disease and heart failure [22]. In Wisconsin, Thao et al. showed that the prevalence of diabetes among the Hmong was $11.3 \%$ compared to $6 \%$ in the non-Hispanic white population [23]. This is supported by another study that concluded that the Hmong are at a high risk of diabetes based on diabetes screening tools, especially the waist circumference and high-risk random blood glucose [24]. In the same context, a study in Minnesota showed that mean systolic and diastolic blood pressure in the Hmong children is higher than that in their white and African American counterparts, which puts them at higher risk of hypertension later in their lives [25].

Interestingly, several studies have been conducted to investigate gout and hyperuricemia among the Hmong after the discovery of the high prevalence of gout among them. It was found that the Hmong have a twofold higher prevalence of gout compared to the non-Hmong population in Minnesota [26]. Similarly, there is a fivefold higher incidence of ureteral and kidney stones among the Hmong compared to the non-Hmong [27]. Moreover, one study revealed that the Hmong had a 31.5\% incidence of tophaceous gout compared to $10.7 \%$ among Caucasians [28]. This study identified a statistically higher prevalence of validated risk alleles in the US Hmong population compared with published data on people of European or Chinese ancestry. Specifically, six out of eight risk alleles were more prevalent in the Hmong than Europeans, and two out of three risk alleles were more prevalent in the Hmong than the Chinese [29]. This observation represents the genetic basis for the higher prevalence of hyperuricemia and gout in the Hmong. Historically, gout is known among the Hmong people as "Crazy Foot" or "Taw Vwm" [30].

Regarding chronic disease management, the Hmong are less likely to pursue treatment as compared to their fellow Asian American counterparts; and when they do, the disease process, such as cancer, is usually detected at a later stage, leading to an increased risk in mortality in this population. Particularly, two studies in California have shown a large discrepancy related to such health-seeking behaviors. One study reported that over $97 \%$ of the Hmong patients deferred treatment for nasopharyngeal cancer as compared to $25.6 \%$ of their Asian/Pacific Islander counterparts $[1,16]$. The second study documented that only $3 \%$ of the Hmong patients diagnosed with hepatocellular carcinoma received treatment in the form of local surgical treatment, resection, or liver transplantation when compared to $22 \%$ of Asian Americans who sought surgical treatment $[1,15]$.

In one study, about $50 \%$ of $323 \mathrm{Hmong}$ adults were found non-compliant with their prescribed hypertension medications [31]. Hmong remedies such as herbs, including plants and tree roots, have been preferentially used by the Hmong to treat diabetes [32]. It was also reported that Hmong markets in Minnesota sold medications that were not approved by the FDA [33]. Fortunately, a survey among the Hmong adults has shown that only $20 \%$ of the Hmong reported the daily use of tobacco, and about $40 \%$ reported ever using tobacco [34]. Additionally, another study has shown that the Hmong have the lowest rate of smoking among all Southeast Asian populations [35].

After working in the Central Valley and having direct contact with the Hmong population, it is evident that there is a disconnect between western medicine and their belief system in terms of dealing with their comorbidities and management plans. Our approach has generally been to utilize a virtual video conferencing interpreter or have an English-speaking family member in the room in the clinical setting. This helps to create a friendly and inviting atmosphere. We recommend outrightly acknowledging the language and culture barrier, as this helps to build trust and overcome the disparities. With any patient, it is only realistic to ask about their expectations for the visit and their future care. Members of the Hmong community are generally welcoming when it comes to discussions about medical management; however, they can be reluctant to make an immediate change. It has been our experience that frequent clinic visits 
help with patient-physician understanding and better overall care. Again, in the inpatient setting, we recommend discussing the disconnect between their culture and western medicine, asking for their expectations in terms of management, and allowing for either a virtual or actual live interpreter. We recommend stationing Hmong-speaking nurses to care for patients of Hmong culture, which would help build rapport. In the critical care scenario, it is important to recognize that a lot of the standard interventions such as central lines, transvenous pacers, arterial lines, and endotracheal tubes may not be a part of their belief system. Hence, constant discussions involving patients' families are necessary. We have observed that, during such discussions, the male members of the family are often primarily involved, and the eldest member is the decision-maker. Recognition of this fact may help with better timing of family meetings to accommodate the eldest male member, as most decisions will be made only with their consent. In our opinion, the biggest barrier to the management of Hmong patients is the failure to recognize their distinct culture and belief systems.

\section{Conclusions}

There are many challenges that practicing providers face when treating people belonging to various ethnic cultures. Overcoming language barriers, poor medical literacy among the patients, their low socioeconomic status, and lack of compliance are just some of the challenges that need to be overcome; however, we believe that the biggest challenge is the ignorance about our patients and their cultural backgrounds. A good patient-provider relationship is of the utmost importance when conveying medical management, which can only be attained by recognizing the differences in their culture and respecting their values/beliefs. We hope that this guide will further minimize the barriers between healthcare providers and the Hmong community and help build that critical patient-provider relationship. We recommend more targeted studies about health-related perceptions and treatments among various ethnicities such as the unique Hmong population.

\section{Additional Information \\ Disclosures}

Conflicts of interest: In compliance with the ICMJE uniform disclosure form, all authors declare the following: Payment/services info: All authors have declared that no financial support was received from any organization for the submitted work. Financial relationships: All authors have declared that they have no financial relationships at present or within the previous three years with any organizations that might have an interest in the submitted work. Other relationships: All authors have declared that there are no other relationships or activities that could appear to have influenced the submitted work.

\section{Acknowledgements}

We would like to thank Hanson Mouanoutoua, MD from UCSF Fresno's Internal Medicine department for his valuable suggestions.

\section{References}

1. Lor M: Systematic review: health promotion and disease prevention among Hmong adults in the USA . J Racial Ethn Health Disparities. 2018, 5:638-661. 10.1007/s40615-017-0410-9

2. Prados J: Jane Hamilton-Merritt: Tragic Mountains: the Hmong, the Americans, and the Secret Wars for Laos, 1942-1992. Bloomington: Indiana University Press. 1993. Am Hist Rev. 1994, 99:530. 10.1086/ahr/99.2.530

3. The State of the Hmong American Community, 2013 . (2013). Accessed: August 17, 2020: http://aapidata.com/wp-content/uploads/2017/04/State-of-the-Hmong-American-Community-2013.pdf

4. Gerdner LA, Cha D, Yang D, Tripp-Reimer T: The circle of life: end-of-life care and death rituals for HmongAmerican elders. J Gerontol Nurs. 2007, 33:20-29. 10.3928/00989134-20070501-05

5. Cha D: Hmong American Concepts of Health, Healing, and Conventional Medicine . Routledge, New York, NY; 2003. 10.4324/9780203488034

6. Johnson SK: Hmong health beliefs and experiences in the western health care system . J Transcult Nurs. 2002, 13:126-132. 10.1177/104365960201300205

7. Hmong in the U.S. fact sheet: Hmong population in the U.S., 2000-2015 . (2015). Accessed: August 17, 2020: https://www.pewsocialtrends.org/fact-sheet/asian-americans-hmong-in-the-u-s/.

8. Yang K: Hmong Americans: a review of felt needs, problems, and community development . Hmong Stud J. 2003, 4:4-8.

9. Plotnikoff GA, Numrich C, Wu C, Yang D, Xiong P: Hmong shamanism. Animist spiritual healing in Minnesota. Minn Med. 2002, 85:29-34.

10. Mills PK, Yang R: Cancer incidence in the Hmong of central California, United States, 1987-94 . Cancer Causes Control. 1997, 8:705-712. 10.1023/a:1018423219749

11. Ross JA, Xie Y, Kiffmeyer WR, Bushhouse S, Robison LL: Cancer in the Minnesota Hmong population . Cancer. 2003, 97:3076-3079. 10.1002/cncr.11443

12. Chen MS Jr, Fang DM, Stewart SL, et al.: Increasing hepatitis B screening for Hmong adults: results from a randomized controlled community-based study. Cancer Epidemiol Biomarkers Prev. 2013, 22:782-791. 10.1158/1055-9965.EPI-12-1399

13. Sheikh MY, Atla PR, Raoufi R, Sadiq H, Sadler PC: Prevalence of hepatitis B infection among young and unsuspecting Hmong blood donors in the Central California Valley. J Community Health. 2012, 37:181-185. 10.1007/s10900-011-9434-y 
14. Sheikh MY, Mouanoutoua M, Walvick MD, Khang L, Singh J, Stoltz S, Mills PK: Prevalence of hepatitis B virus (HBV) infection among Hmong immigrants in the San Joaquin Valley. J Community Health. 2011, 36:42-46. 10.1007/s10900-010-9283-0

15. Kwong SL, Stewart SL, Aoki CA, Chen MS Jr: Disparities in hepatocellular carcinoma survival among Californians of Asian ancestry, 1988 to 2007. Cancer Epidemiol Biomarkers Prev. 2010, 19:2747-2757. 10.1158/1055-9965.EPI-10-0477

16. Dodge JL, Mills PK, Yang RC: Nasopharyngeal cancer in the California Hmong, 1988-2000. Oral Oncol. 2005, 41:596-601. 10.1016/j.oraloncology.2005.01.009

17. Yang RC, Mills PK, Riordan DG: Cervical cancer among Hmong women in California, 1988 to 2000 . Am J Prev Med. 2004, 27:132-138. 10.1016/j.amepre.2004.04.003

18. Her C: Nasopharyngeal cancer and the Southeast Asian patient. Am Fam Physician. 2001, 63:1776-1782.

19. Ng WT, Yau TK, Yung RW, Sze WM, Tsang AH, Law AL, Lee AW: Screening for family members of patients with nasopharyngeal carcinoma. Int J Cancer. 2005, 113:998-1001. 10.1002/ijc.20672

20. Jia WH, Feng BJ, Xu ZL, et al.: Familial risk and clustering of nasopharyngeal carcinoma in Guangdong, China. Cancer. 2004, 101:363-369. 10.1002/cncr.20372

21. Culhane-Pera KA, Moua M, DeFor TA, Desai J: Cardiovascular disease risks in Hmong refugees from Wat Tham Krabok, Thailand. J Immigr Minor Health. 2009, 11:372-379. 10.1007/s10903-008-9211-x

22. Hussein HM, Kashyap B, Erickson LO, Droegemueller C, Hanson L: Abstract WP228: clinical characteristics of Hmong patients presenting with acute ischemic stroke. Stroke. 2017, 48:AWP228. 10.1161/str.48.suppl_1.wp228

23. Thao KK, Arndt B, Tandias A, Hanrahan L: The prevalence of type 2 diabetes mellitus in a Wisconsin Hmong patient population. WMJ. 2015, 114:190-195.

24. Her C, Mundt M: Risk prevalence for type 2 diabetes mellitus in adult Hmong in Wisconsin: a pilot study . WMJ. 2005, 104:70-77.

25. Munger RG, Gomez-Marin O, Prineas RJ, Sinaiko AR: Elevated blood pressure among Southeast Asian refugee children in Minnesota. Am J Epidemiol. 1991, 133:1257-1265. 10.1093/oxfordjournals.aje.a115837

26. Wahedduddin S, Singh JA, Culhane-Pera KA, Gertner E: Gout in the Hmong in the United States . J Clin Rheumatol. 2010, 16:262-266. 10.1097/RHU.0b013e3181eeb487

27. Portis AJ, Hermans K, Culhane-Pera KA, Curhan GC: Stone disease in the Hmong of Minnesota: initial description of a high-risk population. J Endourol. 2004, 18:853-857. 10.1089/end.2004.18.853

28. Portis AJ, Laliberte M, Tatman P, Moua M, Culhane-Pera K, Maalouf NM, Sakhaee K: High prevalence of gouty arthritis among the Hmong population in Minnesota. Arthritis Care Res (Hoboken). 2010, 62:13861391. 10.1002/acr.20232

29. Roman YM, Culhane-Pera KA, Menk J, Straka RJ: Assessment of genetic polymorphisms associated with hyperuricemia or gout in the Hmong. Per Med. 2016, 13:429-440. 10.2217/pme-2016-0021

30. Pinzon-Perez: Health issues for the Hmong population in the U.S.: implications for health educators . Int Electron J Health Educ. 2006, 9:122-133.

31. Wong CC, Mouanoutoua V, Chen MJ, Gray K, Tseng W: Adherence with hypertension care among Hmong Americans. J Community Health Nurs. 2005, 22:143-156. 10.1207/s15327655jchn2203_2

32. Perez MA, Cha K: Diabetes knowledge, beliefs, and treatments in the Hmong population: an exploratory study. Hmong Stud J. 2008, 8:8-28.

33. Grazier MR, Armenian P, Vohra R: Illicit distribution of prescription drugs: report of inadvertent chloroquine toxicity and a market survey of businesses serving ethnic minority populations. Ann Pharmacother. 2014, 48:1070-1076. 10.1177/1060028014535908

34. Rooney BL, Choudhary R, Bliss A: Social determinants of smoking among Hmong Americans residing in Wisconsin. WMJ. 2009, 108:439-446.

35. Constantine ML, Rockwood TH, Schillo BA, et al.: Exploring the relationship between acculturation and smoking behavior within four Southeast Asian communities of Minnesota. Nicotine Tob Res. 2010, 12:715723. $10.1093 /$ ntr/ntq070 